\title{
Wpływ rozwiniętej powierzchni opromieniowanego wymiennika na przejmowanie ciepła
}

\author{
The influence of developed surface of radiationed \\ convector on receiving heat
}

\section{Streszczenie}

Ustalono wpływ stanu rozwinięcia opromieniowanej powierzchni wymienników ciepła na wartości strumienia ciepła unoszonego z wodą przepływającą przez wymienniki umieszczone $\mathrm{w}$ komorze pieca elektrycznego. Nacięcie rowków o głębokości 0,5 i 0,8 mm na obwodzie rurowych wymienników ciepła o średnicy $45 \mathrm{~mm}$ i długości $300 \mathrm{~mm}$ spowodowało ponad dwukrotny wzrost powierzchni wymiany ciepła i odpowiednio w zależności od głębokości rowków około 2 i 1,5 krotny wzrost strumienia ciepła unoszonego z wodą względem wartości uzyskanych w wymiennikach o gładkich powierzchniach.

Słowa kluczowe: wymiennik ciepła, tranfer ciepła, promieniowanie cieplne

\section{Wstęp}

Wszystkie wzory opisujące wymianę ciepła zawierają człon uwzględniający wartość powierzchni wymiany ciepła [1,2].

Podstawowymi sposobami zwiększania wartości powierzchni „czynnej S” bez zwiększania wymiarów konstrukcji urządzeń wymieniających ciepło jest powiększenie ich powierzchni poprzez: mocowanie żeber, igieł, rowkowanie bądź nacinanie zarysu gwintu oraz natryskiwanie powłok o znacznej porowatości otwartej i o dużej odporności na ścieranie.

W szczególności metody rozwinięcia powierzchni powodują zwiększenie absorbcji promienistej ścian uczestniczących w procesach wymiany ciepła z tej racji, iż w odniesieniu do rzutu ścian ich powierzchnia rzeczywista jest wielokrotnie większa. Ponadto absorbcja zwiększa się, dlatego że wgłębienia można uważać za wnęki, których otwory w krańcowych przypadkach mają właściwości ciał czarnych, - co wynika z definicji modelu fizycznego ciała czarnego $[1,2]$.

Praktycznie, więc przy obliczaniu emisji powierzchni chropowatych należy brać pod uwagę powierzchnię styczną do wypukłości oraz współczynnik emisji większy do tego, który charakteryzuje powierzchnię gładką, - co wydatnie zwiększa strumień wymienianego ciepła.

\section{Techniczne ciało czarne i jego model}

Każde ciało posiada emisyjność $(\varepsilon T)$ mniejszą od 1 . Aby absorbcja ciała była jak największa wykorzystuje się efekt wnęki (w).

Powierzchnia otworu wnęki (otworu emitującego $S_{o}$ ) ma znacznie większą emisyjność efektywną $\left(\varepsilon_{\mathrm{T}, \mathrm{f}}\right)$ od rzeczywi-

\section{Abstract}

It the influence of state of radiationed surface of heat convectors on values of heat stream carried away with water which flowed through convectors situated furnace chamber was fixed. Cutting ditches with depth 0.5 and $0.8 \mathrm{~mm}$ which are on the surface of heat convectors which diameter is $45 \mathrm{~mm}$ and length is $300 \mathrm{~mm}$ caused more than double increase of surface and in dependence of ditches depth relatively 2 and 1,5 times increased the heat stream carried away with water.

Keywords: heatexchanger, heat transfer, heat radiation

stej emisyjności materiału wnęki $\left(\mathrm{S}_{\mathrm{rz}}\right)$, której wartości oznacza się przez $\left(\varepsilon_{T}\right)$. Emisyjność otworu wnęki $\left(\varepsilon_{T, e f}\right)$ rośnie ze wzrostem stosunku w - zwanym wnękowością (1) rysunek 1 [1].

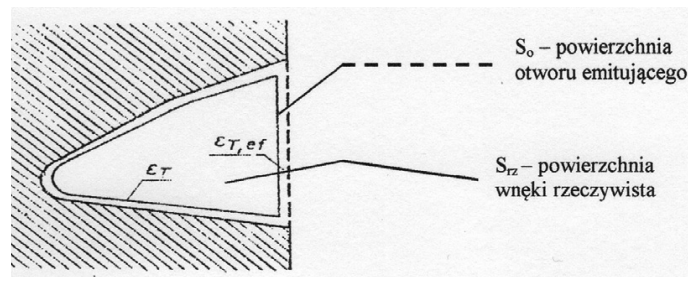

Rys. 1. Wnęka stanowiąca model ciała czarnego [1] Fig. 1. The recess which is a model of black solid

$$
w=\frac{S_{r z}}{S_{0}}
$$

Powierzchnia $\left(\mathrm{S}_{\mathrm{rz}}\right)$ powinna posiadać stałą temperaturę $\mathrm{T}$ w jej każdym punkcie - wówczas jej wartość stanowi temperaturę powierzchni promieniującej $\left(\mathrm{S}_{0}\right)$.

Emisyjność otworu wnęki $\left(\varepsilon_{\mathrm{T}, \mathrm{ef}}\right)$ w funkcji stosunku (w) dla różnych kształtów wnęki przestawiono na rysunku 2 i zapisano równaniem (2).

$$
\varepsilon_{\mathrm{T}} \cdot \text { ef }=\mathrm{f}\left(\varepsilon_{\mathrm{T}} \cdot \mathrm{w}\right)
$$

Wnęki winny mieć wymiary znacznie przewyższające długości emitowanych fal promieniowania podczerwonego. Przy niespełnieniu tego warunku mogą wystąpić odchylenia od praw promieniowania temperaturowego (Plancka, Stefana - Boltzmana). Ponadto można popełnić błędy pomiaru temperatury wywołane między innymi: nieizotermicznością komory i innymi błędami towarzyszącymi pomiarom temperatury.

dr inż. Sławomir Morel - Politechnika Częstochowska.

Autor korespondencyjny/Corresponding author: morel@wip.pcz.pl 


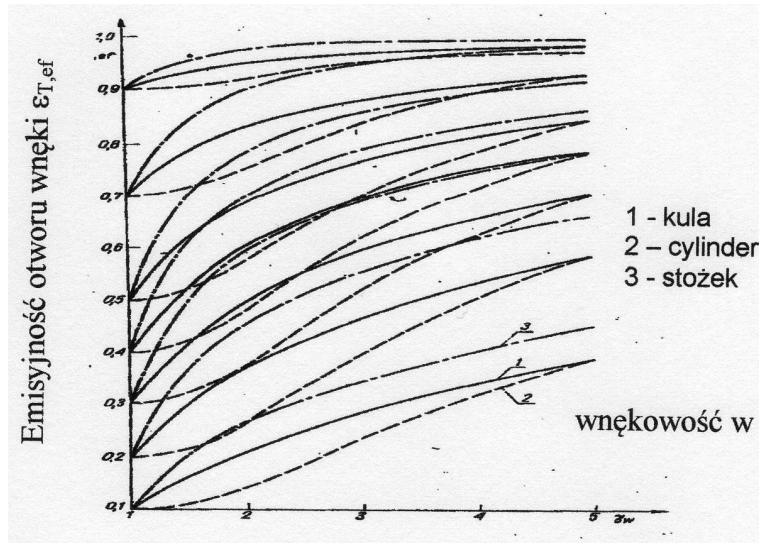

Rys. 2. Wnęka stanowiąca model ciała czarnego [1]

Fig. 2. The recess which is a model of black solid

\section{Absorpcja i emisja promieniowania cieplnego przez metale i niemetale}

Powszechnie przyjmuje się, iż metale o czystej nieutlenionej powierzchni mają emisyjność od kilku setnych do ok. 0,40. Emisyjność dielektryków jest znacznie więk-

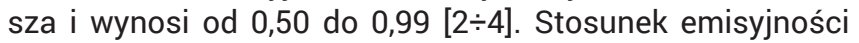
$\varepsilon_{\mathrm{T}} / \varepsilon_{\mathrm{T}}, \mathrm{n}$ jest dla metali większy od 1 , zaś dla dielektryków - mniejszy. Dla metali absorpcyjność monochromatyczna maleje, zaś dla nie metali wzrasta ze wzrostem długości fali padającego promieniowania. Jeśli stan ciał powierzchni nie ulga zmianie to powszechnie przyjmuje się, iż przebieg funkcji $\varepsilon_{\mathrm{T}}$ jest niezależny od temperatury.

Przez natryskiwanie powłok na wyroby metalowe i niemetalowe można bardzo istotnie zwiększyć emisyjność powierzchni ciał rzeczywistych dla określonych zakresów

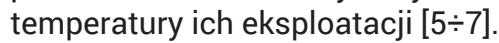

Wzrost zaabsorbowanego ciepła jest funkcją:

- wartości $\varepsilon_{\mathrm{T}}$ wytworzonej powłoki $\left(\varepsilon_{\mathrm{pow}}=0,70-0,95\right)$,

- rozwinięcia opromieniowanej powierzchni natryskanej powłoką tj. wnękowością powłoki (w).

Ten doświadczalny przebieg wzrostu $\left(\varepsilon_{\mathrm{T}}, \mathrm{n}\right)$ wywołany wnękowością powłoki (w) zapisano wzorem (3) [2].

$\varepsilon_{\mathrm{T}, \mathrm{n}}=\frac{\varepsilon_{\mathrm{T}, \mathrm{n}, \mathrm{o}} \cdot \mathrm{W}}{1+(\mathrm{W}-1) \varepsilon_{\mathrm{T}, \mathrm{n}, \mathrm{o}}}=\frac{\varepsilon_{\mathrm{T}, \mathrm{n}, \mathrm{o}} \sqrt{1+4\left(\frac{\mathrm{R}_{\mathrm{z}}}{\mathrm{S}}\right)^{2}}}{1+\left[\sqrt{1+4\left(\frac{\mathrm{R}_{\mathrm{z}}}{\mathrm{S}}\right)^{2}-1}-1\right] \varepsilon_{\mathrm{T}, \mathrm{n}, \mathrm{o}}}$

\section{Absorpcyjność i emisyjność metali}

W procesach promienistej wymiany ciepła przez metale uczestniczy cienka powierzchniowa warstewka o głębokości 0 - 10 -10. Wymianę tę powodują oscylacje atomów i cząstek znajdujących się na powierzchni elementu metalowego.

Emisyjność monochromatyczna z powierzchni metalowej maleje ze wzrostem długości fali (bardzo niekorzystne dla podczerwonego promieniowania). Emisyjność całkowita $\left(\varepsilon_{T, n}\right)$ wzrasta ze wzrostem temperatury, co jest zgodne ze wzorami Hagen-Rubens'a - (rów. 4) [2]

$$
\varepsilon_{(\lambda)}=0,365 \sqrt{\frac{\mathrm{pT}}{\lambda_{0}}}
$$

Jednocześnie Autor pracy [2] ustalił, iż ze wzrostem temperatury maleje refleksyjność a jej wartość jest tym mniejsza im większa jest wnękowość (w) powierzchni.

Obecność warstwy tlenkowej (nawet o minimalnej grubości) na metalach zdecydowanie zwiększa ich zdolność do absorpcji i emisji promieniowania cieplnego nawet stali odpornych na korozje.

\section{Absorpcyjność i emisyjność niemetali}

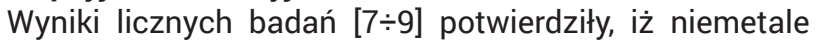
posiadają znacznie większe zdolności do emisji $\left(\varepsilon_{\mathrm{T}}\right)$ promieniowania od metali. Ich emisyjność monochromatyczna wzrasta z długością fali promieniowania, - choć wzrost ten nie jest jednoznaczny jak dla metali.

Emisyjność niemetali maleje zdecydowanie ze wzrostem temperatury.

Tlenki białe (Mg, Al, Th,) posiadają względnie małą emisyjność w zakresie fal o długości od 1 do $5-6 \mu \mathrm{m}$, jednakże dla promieniowania o długości $10 \mu \mathrm{m}$, ich emisyjność posiada wartości zbliżone do współczynnika ciała czarnego.

Tlenki kolorowe (Cr, Ce) mają większą wartość emisyjności w zakresie długości fal w bliskiej podczerwieni względem tlenków białych.

\section{Wpływ rozwiniętej powierzchni wymiennika na przejmowanie promieniowania cieplnego}

Postawiono tezę, iż rozwijając powierzchnie wymiennika ciepła, przykładowo poprzez nacięcie rowków na jego obwodzie uzyska się zwiększenie powierzchni wymiany ciepła, co przy niezmiennych wymiarach gabarytowych spowoduje wzrost ilości zaabsorbowanego ciepła.

Celem badań było ustalenie wpływu głębokości naciętych mechanicznie rowków (o kształcie trójkąta równoramiennego), na rozwinięcie powierzchni oraz doświadczalne potwierdzenie wpływu wielkości rozwiniętej powierzchni na zwiększenie strumienia przejmowanego ciepła z wodą przepływającą przez wymiennik.

Zakres obejmował badania porównawcze wpływu czterech przypadków (wartości) rozwinięcia powierzchni (rur wykonanych ze stali nierdzewnej o jednakowych wymiarach) na wartości strumienia wymienianego ciepła.

Wymienniki stanowiły: rura handlowa z natryskaną powłoką, rura handlowa z natryskaną powłoką i wypolerowana, rura z naciętym zarysem gwintu o głębokości 0,5 mm, rura z naciętym zarysem gwintu o głębokości $0,8 \mathrm{~mm}$.

\section{Stanowisko badawcze i wykonanie pomiarów}

Schemat stanowiska przestawiono na rysunku 3.

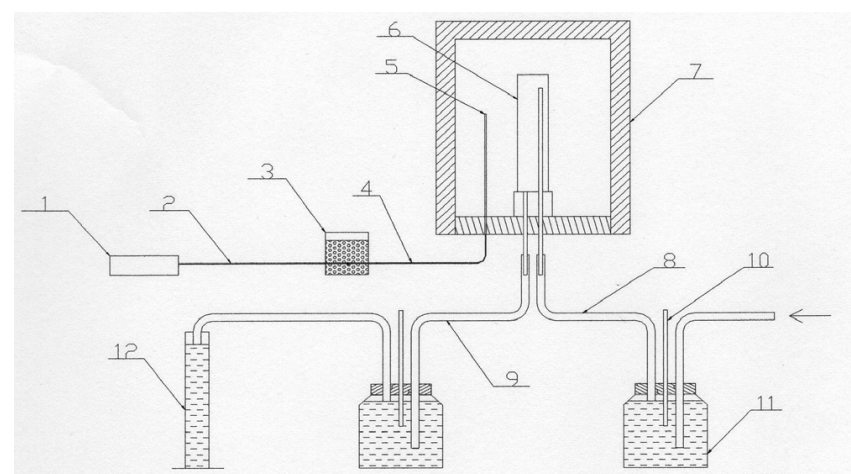

Rys. 3. Schemat stanowiska do badań wpływu rozwinięcia powierzchni na strumień wymienianego ciepła: 1- miliwoltomierz prądu stałego V520, 2- przewody miedziane, 3- naczynie izolowane cieplnie wypełnione drobno potłuczonym lodem, 4- przewód kompensacyjny, 5- termoelement pomiarowy NiAl-NiCr, 6-cztery rury stalowe o jednakowych gabarytach, 7- piec grzewczy, 8- przewód gumowy doprowadzający wodę, 9- przewód gumowy odprowadzający wodę, 10-dwa termometry rtęciowe, 11- dwa hermetyczne zbiorniki, w których zostały umieszczone termometry, 12- zlewka laboratoryjna służąca do pomiaru natężenia przepływu wody.

Fig. 3. Scheme of stand for testing the influence of developed surface 
Wymiennik z podłączonym do niego dwoma przewodami gumowymi doprowadzających i odprowadzających wodę został umieszczony w piecu grzewczym stanowiącym źródło ciepła.

Dwa termometry rtęciowe - pierwszy mierzący temperaturę wody na wejściu do wymiennika o zakresie pomiarowym $0-50{ }^{\circ} \mathrm{C}$, drugi mierzący temperaturę wody na wyjściu o zakresie pomiarowym $0-80{ }^{\circ} \mathrm{C}$. Termometry zostały umieszczone ok. 1 metr od źródła ciepła. Odległość ta pozwoliło na zabezpieczenie przed powstaniem błędu wskazań. Wszystkie elementy układu wodnego zostały połączone przy pomocy przewodów gumowych o średnicy $\varphi=10 \mathrm{~mm}$. Wielkość natężenia przepływu mierzona była przez wodomierz i kontrolowana wyrywkowo za pomocą menzurki laboratoryjnej o pojemności $1 \mathrm{dm}^{3}$ i mierzonego czasu jej napełnienia za pomocą stopera. Temperatura panująca wewnątrz komory pieca była określana za pomocą termoelementu NiAl-NiCr.

Zasada pomiaru polegała na określeniu przyrostu temperatury wody przy ustalonym natężeniu przepływu przez wymiennik i nie zmiennej temperaturze w komorze pieca.

Eksperymentalną część badań wykonano w czterech etapach.

W pierwszym etapie badań wykorzystano rurę handlową, wykonaną ze stali nierdzewnej o średnicy $\varphi=45,25 \mathrm{~mm}$ oraz długości I= $300 \mathrm{~mm}$ z natryskaną powłoką z $\mathrm{Cr}_{2} \mathrm{O}_{2}$.

W drugim etapie badań wykorzystano rurę z powłoką $\mathrm{z} \mathrm{Cr}_{2} \mathrm{O}_{2}$ ale jej powierzchnię wypolerowano, o średnicy $\varphi=45,10 \mathrm{~mm}$ oraz długości I $=300 \mathrm{~mm}$.

Każdy z wyżej wymienionych etapów badań rozpoczynano po uprzednim rozgrzaniu komory pieca. Za pomocą termometrów rtęciowych stale mierzono wartości temperatury wody wpływającej i wypływającej z wymiennika ciepła. $\mathrm{Na}$ bieżąco kontrolowano również termoelementem temperaturę wewnątrz pieca wynoszącą $-700{ }^{\circ} \mathrm{C}$. Odczytów dokonywano co $15 \mathrm{~min}$. Pomiary powtarzano sześciokrotnie, co wobec dużej powtarzalności wyników uznano za wystarczającą ilość prób. We wszystkich etapach pomiary dokonywano dokładnie $\mathrm{w}$ ten sam sposób, starając się zachować takie same natężenia przepływu wody.

Wyniki czterech serii pomiarów zamieszczono w pracy [3].

\section{Wyniki pomiarów i ich analiza}

\section{Wyznaczenie powierzchni rozwiniętej wymiennika}

- Wymiennik - z rury handlowej $\varphi=45,25 \mathrm{~mm} \mathrm{I}=300 \mathrm{~mm}$ $S=\pi \cdot d \cdot I=3,14 \cdot 45,25 \cdot 300=42484,2 \mathrm{~mm}^{2}=0,0426 \mathrm{~m}^{2}$

- Wymiennik - z rury wypolerowanej $\varphi=45,10 \mathrm{~mm} \mathrm{I}=300 \mathrm{~mm}$ $S=\pi \cdot d \cdot I=3,14 \cdot 45,10 \cdot 300=42625,5 \mathrm{~mm}^{2}=0,0425 \mathrm{~m}^{2}$

- Wymiennik - z rury z naciętym zarysem rowka o głębokości 0,5 mm

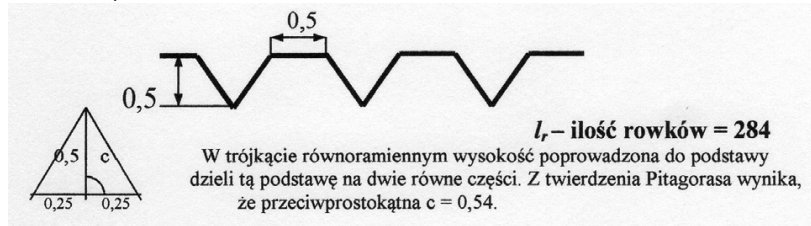

$\mathrm{S}=\pi \cdot d \cdot(2 \cdot c+0,5) \cdot \mathrm{I}_{\mathrm{r}}=3,13 \cdot 45,25 \cdot(2 \cdot 0,54+0,5) \cdot 284=$ $=62142,3 \mathrm{~mm}^{2}=0,0621 \mathrm{~m}^{2}$

- Wymiennik - z rury z naciętym zarysem rowka o głębokości 0,8 $\mathrm{mm}$.

0,8

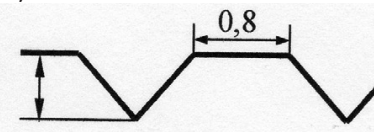

$l_{r}-$ ilość rowków $=168$

$S=\pi \cdot d \cdot 2 \cdot c+0,8) \cdot I_{r}=3,14 \cdot 42,25 \cdot(2 \cdot 0,89+0,8) \cdot 168=$ $=57502,3 \mathrm{~mm}^{2}=0,0575 \mathrm{~m}^{2}$
Wyniki badań przeprowadzonych $\mathbf{w}$ etapie I

W etapie I w charakterze wymiennika zastosowano wymiennik z rury handlowej o średnicy $\varphi=45,25 \mathrm{~mm}$ a uzyskane wyniki opracowano graficznie na rysunku 4.

\section{Analiza wyników I - go etapu}

Średnia temperatura wody na dopływie do wymiennika $12,2^{\circ} \mathrm{C}$, powierzchnia wymiany ciepła wyniosła $42625,5 \mathrm{~mm}^{2}$ umieszczonego w laboratoryjnym piecu grzewczym o temperaturze $700{ }^{\circ} \mathrm{C}$. Po przejściu przez wymiennik średnia temperatura wody wzrosła do $29^{\circ} \mathrm{C}$. Średnie natężenie strumienia wody przepływającej przez w/w rurę wynosiło 0,033 $\mathrm{m}^{3} / \mathrm{h}$.

Obliczony strumień ciepła zaabsorbowanego przez wodę osiągnął wartość 2,196 kW.

\section{Wyniki badań przeprowadzonych w etapie II}

W etapie tym badania przeprowadzono stosując wymiennik z rury o wypolerowanej powierzchni o śr. $\varphi=45,10 \mathrm{~mm}$. Wyniki opracowano graficznie (rys. 4). Podobnie jak w etapie I korzystano z tej samej aparatury kontrolno-pomiarowej.

\section{Analiza wyników II- go etapu}

W przypadku zastosowania rury wypolerowanej osiągnięto następujące wyniki:

- średnia różnica temperatury wody wpływającej i wypływającej - $15,4^{\circ} \mathrm{C}$,

- spadek temperatur średniej różnicy w porównaniu z etapem I osiągnął wartość $-1,4^{\circ} \mathrm{C}$,

- natężenie strumienia przepływu $-0,035 \mathrm{~m}^{3} / \mathrm{h}$,

- temperatura wewnątrz pieca $-700{ }^{\circ} \mathrm{C}$,

- średnia wartość strumienia ciepła -2,151 kW.

Stosując rurę wypolerowaną uzyskano spadek wartości strumienia przejmowanego ciepła o ok. $2 \%$ w stosunku do wartości uzyskanej dla rury handlowej. Uzyskany wynik uzasadnia zmniejszenie opromieniowanej powierzchni wymiany ciepła o $141,3 \mathrm{~mm}^{2}$ oraz zwiększenie zdolności do refleksyjnego odbijania promieniowania cieplnego $z$ racji wykonanego polerowania na rurze.

\section{Wyniki badań przeprowadzonych w etapie III}

Wyniki badań przeprowadzonych w etapie III z zastosowaniem rury z naciętym zarysem rowka o głębokości 0,5 mm przedstawiano na rysunku 4.

\section{Analiza wyników III- go etapu}

Średnia temperatura wody przy dopływie do rury z naciętymi 284 rowkami w kształcie trójkątów równoramiennych o ramieniu długości $0,54 \mathrm{~mm}$ i podstawie $0,5 \mathrm{~mm}$ wynosiła $12,1^{\circ} \mathrm{C}$. Temperatura zmierzona na wypływie $-30,6^{\circ} \mathrm{C}$. Strumień wody przepływającej przez wymiennik wynosił $0,057 \mathrm{~m}^{3} / \mathrm{h}$. Ciepło zaabsorbowane przez wodę osiągnęło wartość 4,195 kW. Tak, więc w stosunku do rury handlowej nastąpił wzrost strumienia ciepła o $2 \mathrm{~kW}$. Uzyskano, zatem 92\% wzrost strumienia przejmowanego ciepła przez wodę w porównaniu z wartością strumienia osiągniętego przy zastosowaniu rury handlowej.

Należy to uzasadnić zwiększeniem powierzchni wymiany ciepła o ok. $115 \%$ względem wartości dla rury bazowej oraz wystąpieniem efektu wnęki - zwiększenia stopnia czarności opromieniowanej powierzchni, co doprowadziło do uzyskania tak znacznego wzrostu strumienia przejmowanego ciepła.

\section{Wyniki badań przeprowadzonych w etapie IV}

W etapie IV do badań użyto rury z naciętym zarysem rowka o głębokości $0,8 \mathrm{~mm}$ w liczbie 168 rowków/na rurę. Podobnie jak w etapie I, II i III dokonano sześciu pomiarów wykorzystując piec o temperaturze $700{ }^{\circ} \mathrm{C}$, kontrolowany przy pomocy miliwoltomierza. Zestawienie wyników przedstawia rysunek 4. 
Analiza wyników IV-go etapu

Postępując analogicznie do etapu I, II, III uzyskano następujące wyniki:

- temperatura wody na dopływie $-13,9^{\circ} \mathrm{C}$,

- temperatura wody na wypływie $-28,{ }^{\circ} \mathrm{C}$,

- spadek średniej różnicy temperatur w porównaniu z etapem III $-3,6^{\circ} \mathrm{C}$,

- powierzchnia wymiany ciepła - $130032 \mathrm{~mm}^{2}$,

- natężenie strumienia wody przepływającej przez rurę $-0,060 \mathrm{~m}^{3} \mathrm{~h}$,

- zaabsorbowany przez wodę strumień ciepła - 3,506 kW - wzrost w stosunku do rury handlowej o 1,312 kW (ok. 60\%)

Porównując wartości strumienia przejmowanego ciepła z wynikami uzyskanymi w etapie trzecim otrzymano ok. 16\% spadek badanej wielkości. Wynika to, przede wszystkim

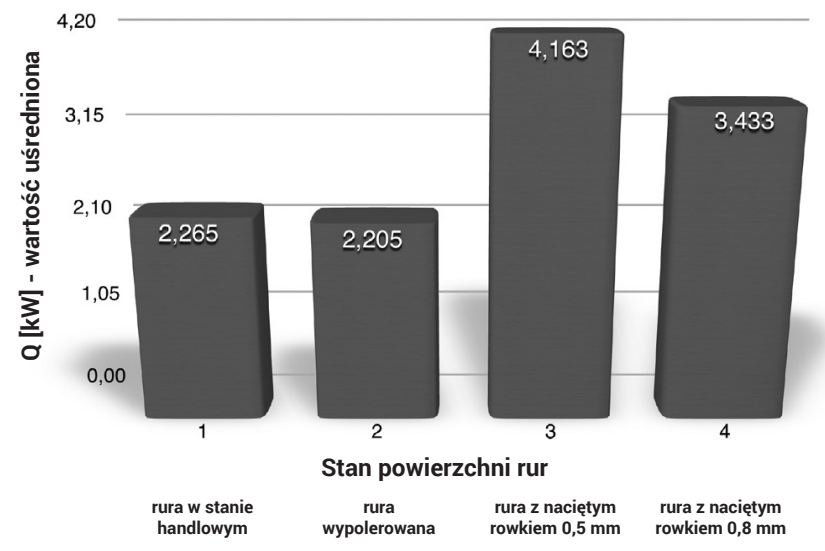

Rys. 4. Strumień przejmowanego ciepła przez poszczególne rodzaje wymienników (rur)

Fig. 4. The stream of receiving heat ze zmniejszenia powierzchni wymiany ciepła o ok. 15\% względem rury z naciętym zarysem rowka o głębokości $0,5 \mathrm{~mm}$ (użytej w trzecim etapie badań).

Wykonane pomiary przejmowania ciepła z zastosowaniem czterech wymienników różniących się rozwinięciem powierzchni pozwoliły ustalić wpływ rozwinięcia powierzchni na wartości strumieni cieplnych przejmowanych przez wodę. Powierzchnia wymiany ciepła wynosiła odpowiednio:

- rura handlowa - 4,262 $\mathrm{dm}^{2}$ a strumień ciepła 2,20 kW,

- rura wypolerowana $-4,248 \mathrm{dm}^{2}$ a strumień ciepła $2,15 \mathrm{~kW}$,

- rura z naciętym zarysem rowka (gł. 0,5 mm) - 6,214 dm² a strumień ciepła 4,20 kW,

- rura z naciętym zarysem rowka (gł. 0,8 mm) - 5,750 dm² a strumień ciepła $3,50 \mathrm{~kW}$.

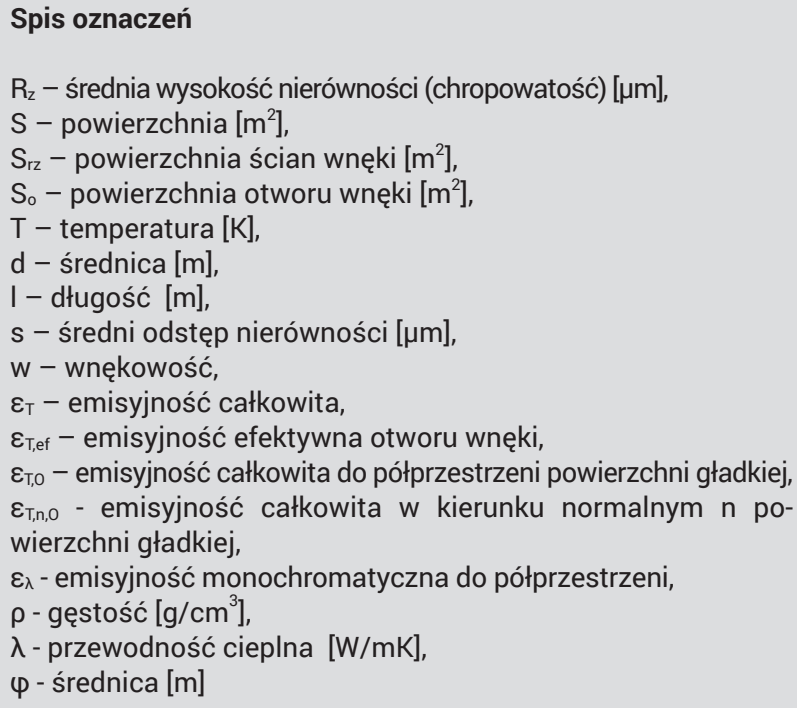

\section{Wnioski}

W badaniach ograniczono się do jednego rodzaju powłoki natryskanej plazmowo z tlenku chromu $\mathrm{Cr}_{2} \mathrm{O}_{3}$ na powierzchnię wymiennika. Przy czym stosując w charakterze wymiennika rurę z wypolerowaną powierzchnią uzyskano najmniejszą wartość strumienia przejmowanego ciepła względem wyników uzyskanych z zastosowaniem pozostałych rodzajów rur. Dokonując niewielkiej „obróbki” rury handlowej poprzez wypolerowanie uzyskano spadek wymiany ciepła o ok. $2 \%$ względem wartości uzyskanych na rurze handlowej. Spadek ten jak wcześniej wyszczególniono spowodowany został zmniejszeniem o 0,014 dm² powierzchni wymiany ciepła oraz wzrostem zdolności do refleksyjnego odbijania promieniowania cieplnego.

W etapie III zastosowano rurę z natryskaną powłoką z $\mathrm{Cr}_{2} \mathrm{O}_{3}$ oraz naciętymi rowkami o głębokości 0,5 mm. Przez nacięcie 284 rowków opromieniowana powierzchnia rury (wymiennika) wzrosła o ok. 115\% - co doprowadziło do dwukrotnego wzrostu strumienia ciepła przejmowanego przez wodę przepływającą przez ten wymiennik w porównaniu do wymiennika bez rowków.

Uzyskane wyniki dobitnie świadczą o istotności wpływu rozwinięcia powierzchni na wymianę ciepła i celowości stosowania tego typu zabiegu.

Dokonując pomiarów z zastosowaniem rury z naciętymi rowkami o głębokości $0,8 \mathrm{~mm}$ rozwinięta powierzchnia zmniejszyła się w stosunku do wartości dla rury wykorzystanej w etapie trzecim $(0,5 \mathrm{~mm})$ o ok. $15 \%$. Natomiast wzrost przejmowanego strumienia ciepła w tym wymienniku zmniejszył się o ok. 16\%.

Reasumując stwierdza się, iż rozwijając powierzchnie wymiany ciepła przez nacięcie odpowiedniej ilości rowków o odpowiedniej głębokości można zwiększyć ilość zaabsorbowanego ciepła nawet o ok. 200\%.

\section{Literatura}

[1] A. Sala: Radiacyjna wymiana ciepła Wyd. WN-T Warszawa, 1982, str. 18-43.

[2] B.G. Abrgmowicz, W.t. Goldsztein: Intienisifikacja tiepłobmiena izłuczeniem s pomoszczju pokrytej. Wyd. Eniergia Moskwa, 1977, str. 26-39.

[3] St. Morel: Powłoki natryskiwanie cieplnie. Monografia. Wyd. WIPMiFS, Politechnika Częstochowska, Częstochowa 1990.

[4] S. Morel: Application of Plasma-Sprayed Coatings in Heat Absorption by Radiated Walls.

[5] Archive of Energetics / Archiwum Energetyki T.41 nr 3-4, 2011, s. 111-126.

[6] T.Burakowski, T.Wierzchoń Inżynieria powierzchni metali Wyd. WN-T Warszawa 1995.
[7] T.Węgrzyn, J. Piwnik: Low alloy welding with mocro-jet cooling Archives of Metllurgy and Materials. vol. 57, Iss 2, 2012.

[8] S. Morel: Zastosowanie powłok plazmowych w hutniczych urządzeniach grzewczych. Hutnik-Wiadomości Hutnicze R.78 nr 5, 2011, s. $449-451$.

[9] S. Morel, J. Jasiński, J. Jasiński, L. Jeziorski: Powłoki natryskiwane plazmowo na elementach urządzeń do fluidalnej obróbki cieplnej. Inżynieria Materiałowa R.33, nr 5 (189), 2012, s. 456-459.

[10] T. Hejwowski: Nowoczesne powłoki nakładane cieplnie odporne na zużycie ścierne i erozyjne. Wyd. Politechnika Lubelska 2013. 